\title{
The microcircuit concept applied to cortical evolution: from three-layer to six-layer cortex
}

\section{Gordon M. Shepherd*}

Department of Neurobiology, Yale University School of Medicine, New Haven, CT, USA

\section{Edited by:}

Fernando Martinez-Garcia, Universidad

de Valencia, Spain

Reviewed by:

Bartlett W. Mel, University of Southern

California, USA

Arnold Kriegstein, University of

California San Francisco, USA

${ }^{*}$ Correspondence:

Gordon M. Shepherd, Department of Neurobiology, Yale University School of

Medicine, 333 Cedar Street, New

Haven, CT 06510, USA.

e-mail: gordon.shepherd@yale.edu
Understanding the principles of organization of the cerebral cortex requires insight into its evolutionary history. This has traditionally been the province of anatomists, but evidence regarding the microcircuit organization of different cortical areas is providing new approaches to this problem. Here we use the microcircuit concept to focus first on the principles of microcircuit organization of three-layer cortex in the olfactory cortex, hippocampus, and turtle general cortex, and compare it with six-layer neocortex. From this perspective it is possible to identify basic circuit elements for recurrent excitation and lateral inhibition that are common across all the cortical regions. Special properties of the apical dendrites of pyramidal cells are reviewed that reflect the specific adaptations that characterize the functional operations in the different regions. These principles of microcircuit function provide a new approach to understanding the expanded functional capabilities elaborated by the evolution of the neocortex.

Keywords: olfactory cortex, dorsal general cortex, hippocampus, neocortex, pyramidal neuron, recurrent excitation recurrent inhibition, apical dendrite
Recent evidence is allowing the patterns of synaptic organization in different brain regions to come more clearly into focus. These patterns have been characterized by various terms, including organization by contact (Ramon y Cajal, 1911), synaptic organization, basic circuit (Shepherd, 1974), local circuit (Rakic, 1976), canonical circuit (Douglas et al., 1989), and microcircuit (Byrne et al., 1978; Shepherd, 1978, 1994; Grillner et al., 2005; Graybiel and Grillner, 2006; Shepherd and Grillner, 2010). Whatever the terms used, the concepts are proving increasingly important in helping to guide experimental analysis of a system and construct computational simulations that aid the experimental analysis.

A brain microcircuit has been defined as the organization of nerve cells into specific patterns that carry out the information processing characteristic of a given brain region. This concept has been used to test whether it can provide the basis for comparing the principles of organization across different brain systems, in order to identify common principles as well as the special adaptations for each region. An early example was common principles across phyla in comparing mammalian and insect olfactory systems (Hildebrand and Shepherd, 1997). Microcircuits for over 50 brain regions, in both vertebrates and invertebrates, have been recently published (Shepherd and Grillner, 2010).

If this approach has merit in comparing different brain systems, it should be of further value in comparing systems for insights into evolution. Here we apply this approach to the evolution of the cerebral cortex. The key problem is well recognized. The cerebral cortex of fish, amphibians and reptiles is characterized by three layers, whereas mammals have developed a new type of "neocortex" with six layers (reviewed in Striedter, 2005). One of the most challenging problems in vertebrate evolution is understanding how this happened. (Solving this problem is not helped by the confusing terminology for the different parts of the cortex: see Swanson, 2000 for a discussion of this question.)
The problem is usually addressed looking backward from the neocortex. An alternative is a prospective view, beginning with three-layer cortex. This started with early work on olfactory cortex, perhaps the region of the cerebral cortex least changed through vertebrate evolution, hippocampus, and reptilian dorsal cortex. In the mammal, three-layer cortex persists in the olfactory cortex and the hippocampus. Early work (Shepherd, 1974, 1988; Smith et al., 1980; and Kriegstein and Connors, 1986) provided evidence for the hypothesis that these regions of three-layer cortex contain the basic microcircuit core that has been elaborated in six-layer neocortex.

This review will update that hypothesis, drawing together earlier and more recent work on cortical microcircuits to provide new evidence for how this might have occurred. A broad synthesis such as this is needed not only for fresh approaches to the problem of neocortical evolution, but also for providing a framework for integrating parallel approaches using molecular and genetic approaches. This framework should also contribute eventually to a better understanding of the new functions enabled by a neocortical architecture. I apologize that space does not permit citing of all the relevant literature.

\section{CORTICAL MICROCIRCUITS: THE BASIC HYPOTHESIS}

The traditional method for analyzing brain evolution has been neuroanatomy, with a focus on comparing such features as size and number of brain areas, patterns of cell lamination, and the connections between areas. However, a new approach at the cellular and microcircuit level became possible in the 1970s with the new studies revealing patterns of synaptic organization. This provided the first evidence for basic patterns of organization that are similar across different regions. This included the three main regions of the mammalian cerebral cortex: olfactory cortex, hippocampus, and neocortex. On this basis: 
It is suggested that the study of synaptic organization provides a basis for distinguishing certain characteristics of local organization that may be termed cortical.... It implies that certain modes of information processing are possible with a cortical type of organization that are not possible with other, noncortical, types.

...the study of synaptic organization [is] the necessary basis for understanding the particular contribution of the cortex to mammalian and human behavior. (Shepherd, 1974)

One of the first basic cortical circuits to be identified was of mammalian olfactory cortex. Figure 1 (top) provides a reminder that olfactory cortex is defined as the main region that receives direct input through the lateral olfactory tract (LOT) from the output cells (mitral and tufted) of the olfactory bulb. We focus here on the region occupying the piriform cortex beneath and adjacent to the LOT. The hippocampus is located in the medial temporal area, and neocortex in the dorsal part, as we discuss below.

We begin by noting several features of the anatomy of the cells. First, the principal neurons have apical dendrites with radial parallel orientations; second, the principal neurons are situated within a framework of a non-repeating sequence of layers; and third, the principal neurons are graded in their size and morphology in the different layers. We will see these properties repeated in all the cortices of the forebrain.
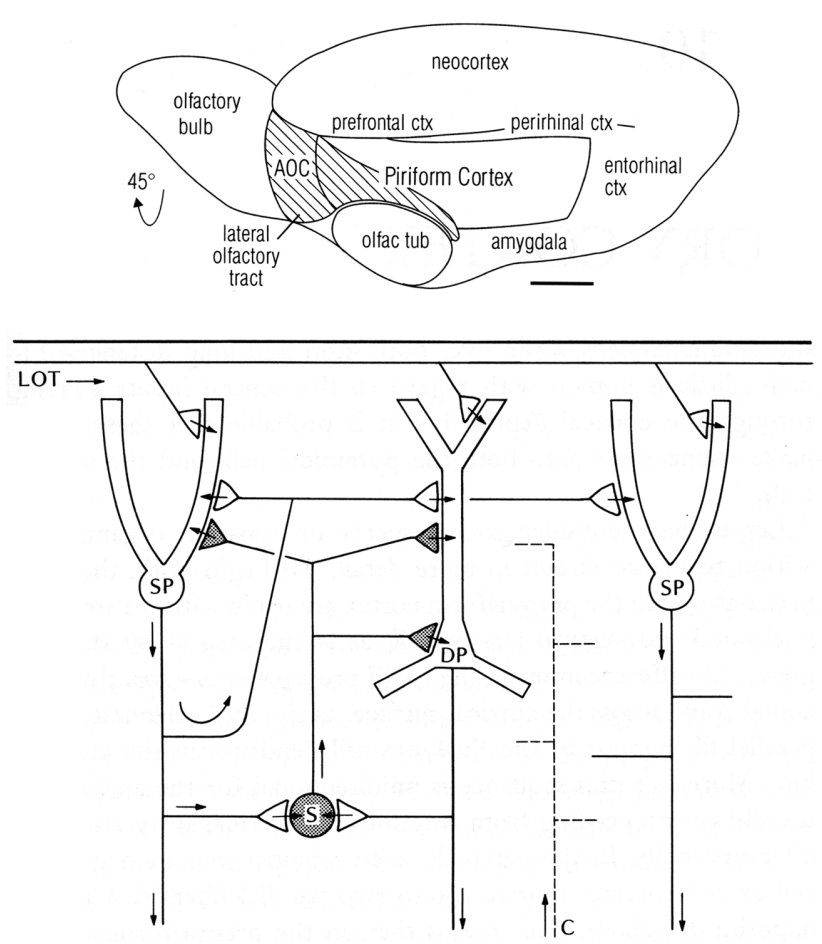

FIGURE 1 |Top: Olfactory cortical areas on the ventrolateral surface of the cerebrum of the rat. Abbreviations: $\mathrm{AOC}$, anterior olfactory cortex; ctx, cortex; olfac tub, olfactory tubercle. From Neville and Haberly (2004). Bottom: Basic circuit of the mammalian piriform (olfactory) cortex. Abbreviations: LOT, lateral olfactory tract; SP, superficial pyramidal cell; DP, deep pyramidal cell; S, stellate cell; $\mathrm{C}$, centrifugal fiber. Arrows indicate direction of flow of activity. Open profiles: excitatory synaptic action; filled profiles: inhibitory synaptic action. From Shepherd (1974).
Single cell recordings from the cat, and from a primitive mammal, the opossum, revealed the basic EPSP-IPSP responses of pyramidal cells to single shocks in the LOT, and the responses of interneurons (Biedenbach and Stevens, 1969; Haberly, 1973a,b). This provided a local circuit for excitation of the pyramidal cells through their distal apical dendrites, and recurrent feedback inhibition through their axon collaterals onto interneurons. A key further finding, using current source density analysis, was of pyramidal cell recurrent excitatory collaterals back onto pyramidal cell apical dendrites (Haberly and Shepherd, 1973).

To summarize these results, a basic circuit was composed, consisting of distal dendritic excitatory input to the pyramidal cells, which then generate recurrent excitation (RE) and recurrent inhibition (Haberly and Shepherd, 1973; see Figure 1 bottom). These three synaptic operations were proposed to be key features of cerebral cortex in general (Shepherd, 1974).

The first place to test this hypothesis was the other main type of three-layer cortex in the mammal, the hippocampus. The basic anatomical connections within the hippocampus had been laid out by Ramon y Cajal (1911). The electrophysiology of the hippocampal pyramidal cell began with Andersen (1960) and Kandel et al. (1961), and the functional organization of the hippocampal circuits began to be revealed by the new work in the hippocampal slice (Andersen et al., 1971; Skrede and Westgaard, 1971). This gave rise to the classical three-synapse model (Figure 2).

At first glance the hippocampal circuit seems different from the olfactory cortex, with the special relay through the dentate gyrus, and the sequence of activation of CA3 followed by CA1. However, there are similarities: the excitatory inputs to the apical dendrites of CA3 and CA1 pyramidal cells, the recurrent excitatory axon collaterals of CA3 pyramidal cells onto CA3 and CA1 pyramidal cells, and the activation of local inhibitory feedback, could be seen as adaptations of the simpler architecture of the olfactory cortex.

Compared with these early successes, studies of the basic connectivity within the mammalian neocortex had barely begun. Nonetheless, evidence was obtained for thalamocortical activation of pyramidal cells, and the two types of actions through their axon collaterals: direct RE, and recurrent inhibition through inhibitory interneurons (see Phillips, 1959). There was an additional circuit element, thalamocortical activation through stellate cells onto the pyramidal cells, which could be viewed as analogous to the situation in the dentate and hippocampus, as an additional internal relay in the input pathway. An early version of the basic circuit for neocortex is shown in Figure 3.

In comparing these three early basic circuits, the common elements are evident: activation through apical dendrites, RE, and recurrent and lateral inhibition, both playing back onto different levels of the apical dendrites. That these basic features of the threelayer cortices should be embedded in the neocortex carried the seeds of a new way of thinking about cortical evolution.

\section{TURTLE DORSAL CORTEX}

This new way of thinking was stimulated by studies in reptilian forebrain of dorsal cortex, also called general cortex. This receives input from the thalamus, and is of special interest as occupying a position which can be regarded as a precursor of neocortex, based 


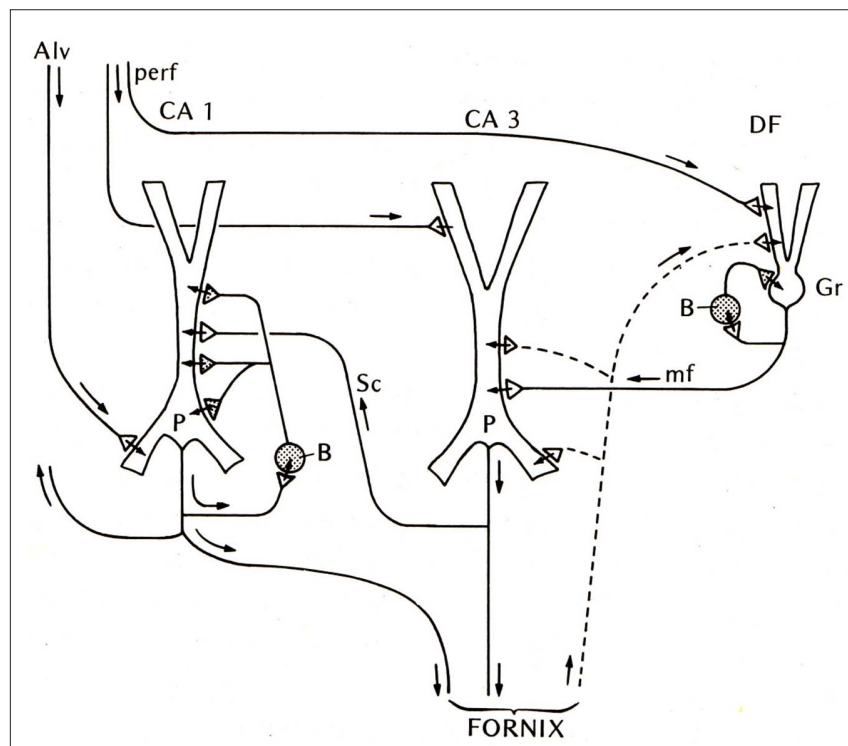

FIGURE 2 | Basic circuit of the mammalian hippocampus and dentate fascia. Abbreviations: Alv, alveus; perf, perforant pathway; CA1, CA3: regions of the hippocampus; DF, dentate fascia; P, pyramidal cell; B, basket cell; Gr, granule cell; mf, mossy fiber; Sc, Schaffer collateral. Arrows indicate direction of flow of activity. Open profiles: excitatory synaptic action; filled profiles: inhibitory synaptic action. From Shepherd (1974).

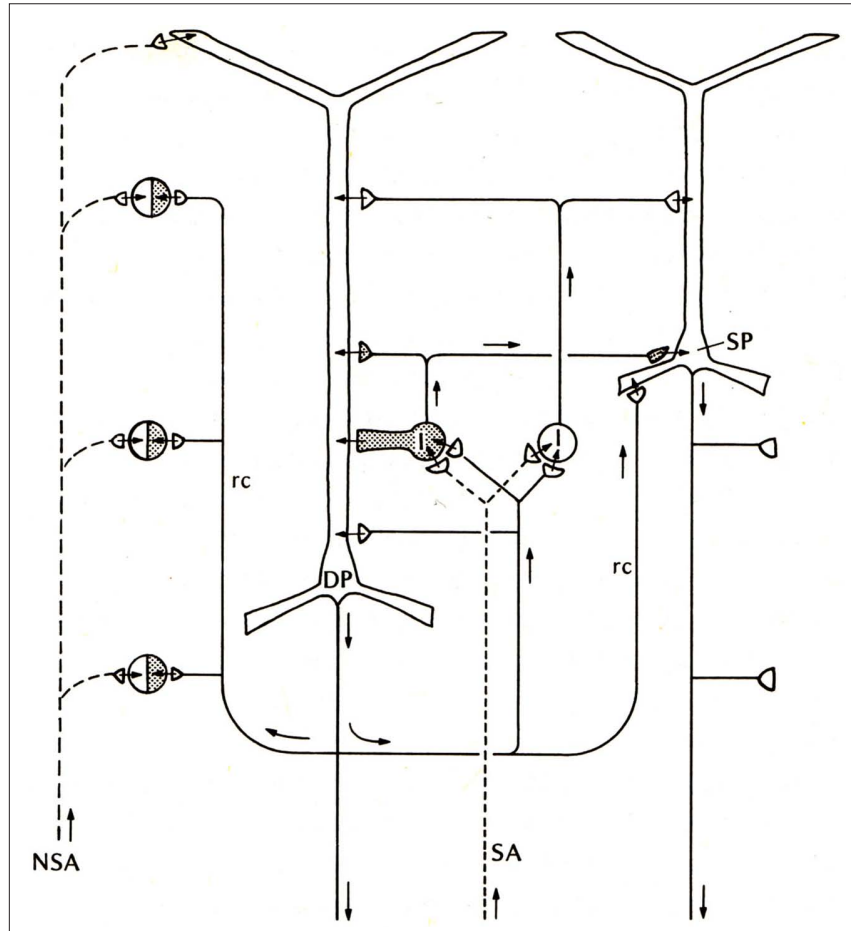

FIGURE 3 | Basic circuit of the mammalian neocortex. Abbreviations: SA, specific sensory afferents; NSA, non-specific sensory afferents; DP, deep pyramidal cell; SP, superficial pyramidal cell; I, intrinsic neurons (excitatory stellate cells and inhibitory interneurons are lumped together); rc, recurrent collateral. Arrows indicate direction of flow of activity. Open profiles: excitatory synaptic action; filled profiles: inhibitory synaptic action. From Shepherd (1974). on its position, shown in Figure 4 (left), on the dorsal surface of the forebrain, flanked on either side by the olfactory cortex and hippocampus. The strategy of exploring this cortex was explicit in a pioneering study by Smith et al. (1980):

We have been studying cortical organization in the adult turtle because this neural system is simple enough for quantitative analysis, yet similar enough in its extrinsic connections to provide a model for some features of mammalian neocortex.

Building on previous studies in mammals using electronmicroscopy to observe degenerating axon terminals following unilateral ablation of the thalamus, they found synaptic connections onto spines of pyramidal cells and smooth dendrites of stellate interneurons. This suggested a pattern of organization in which there are feedforward as well as feedback inhibitory connections from stellate cells onto pyramidal cells (see Figure 4).

Stimulated by this anatomical study and the previous physiological studies of cortical organization, Connors and Kriegstein (1986; also Kriegstein and Connors, 1986) then undertook a landmark study to characterize the electrophysiological properties of these cells in a slice preparation of the turtle dorsal cortex. Using a combination of cell labeling, focal electrical stimulation, and responses to single volleys, they characterized the synaptic connections and physiological properties of both the pyramidal and stellate cells. Consistent with Smith et al. (1980), they found that thalamic afferents excite both pyramidal cell distal dendrites and stellate cells. They also obtained evidence that the stellate cells provide for both feedforward and feedback inhibition of the pyramidal cells. Finally, they also showed feedback excitation from the pyramidal cells back onto pyramidal cells.

They integrated their results by building on the circuit diagram of Smith et al. (1980). As shown in Figure 5, they also took into account the previous basic circuit diagrams for the other types of cortices in order to make comparisons with them. They summarized their conclusions as follows (Kriegstein and Connors, 1986):

The general synaptic organization of turtle general cortex shows striking similarities with those of other cerebral cortical structures, including the pyriform cortex, hippocampus, and neocortex of several well-studied mammalian species (Shepherd, 1979). Each cortex has a principal cell type (or group of subtypes) that features prominent, spinous apical dendrites, and one or more types of sparsely spinous, GABA-utilizing interneuron. Similarities exist for both the general plan of local circuitry and the physiology of the synapses themselves. The uniqueness of each cortex is, of course, specified by many differences of organization. A comparison of these properties between and within species may yield clues about the principles of cortical function and its evolution.

The work of Smith et al. (1980) and of Kriegstein and Connors (1986) thus combined the previous work in the other cortical regions to suggest a new approach to understanding cortical evolution, focused on analysis of intrinsic circuit organization in different regions with detailed comparisons between them of specific circuits for basic functional operations.

\section{SUMMARY OF THE EARLY CONCEPTS}

These early studies were summarized in a review (Shepherd, 1988) whose aim was to test the original proposal that "there is a set of basic principles that governs the organization of intrinsic circuits 

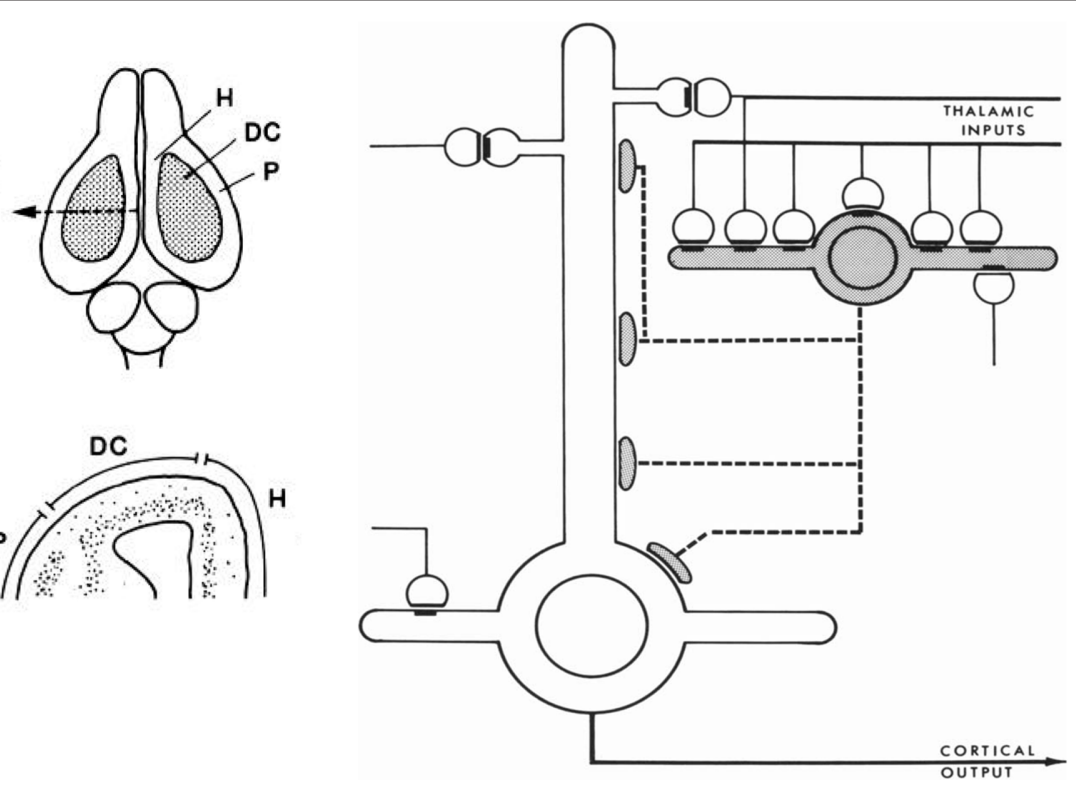

FIGURE 4 | Left, above: Dorsal view of the turtle brain. Abbreviations: DC, dorsal cortex; $\mathrm{H}$, hippocampus; P, piriform (olfactory) cortex. Below, cross section of forebrain at level of arrow in top diagram. From Connors and Kriegstein (1986). Right: Model of circuit in turtle dorsal cortex based on degeneration studies of connectivity from the thalamus and resulting calculations. The circuit is dominated by massive thalamic input to inhibitory interneurons, which provide massive feedforward inhibition to the pyramidal neurons. Both pyramidal cells and interneurons also receive excitatory input from unspecified sources. Open profiles: excitatory synaptic action; filled profiles: inhibitory synaptic action. From Smith et al. (1980).

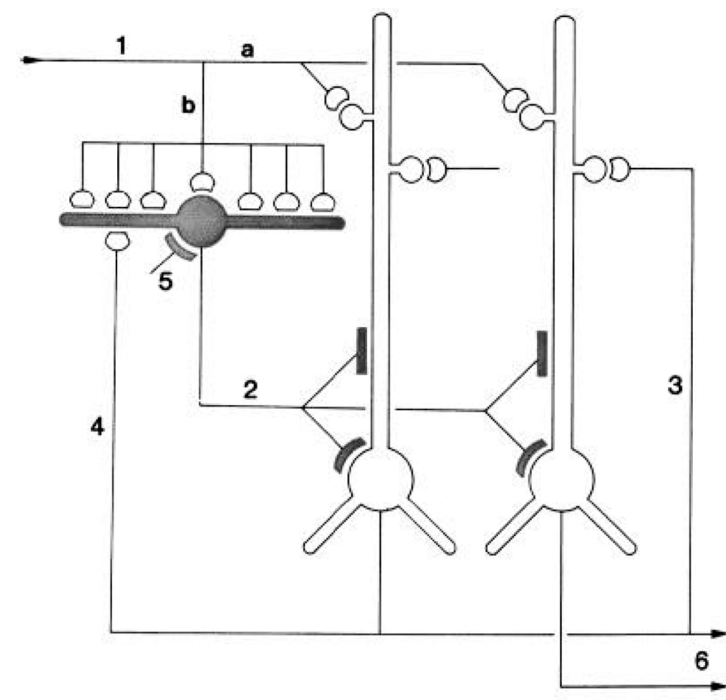

FIGURE 5 | "Schematic diagram of the principal intracortical connections of the turtle visual cortex based on neuroanatomical data (Smith et al., 1980) and the physiological observations reported here. Thalamocortical afferent volleys (1) provide direct excitation of pyramidal cell dendrites (a) and also powerfully excite inhibitory stellate cells (b). Feedforward inhibition is mediated by stellate cell-pyramidal cell contact (2). Local pathways also mediate reciprocal excitation between pyramidal cells (3) as well as feedback inhibition through pyramidal cell-stellate cell conact (4). There is also physiological support for inhibition of stellate interneurons (5), presumably arising from stellate cell-stellate cell contact. The pyramidal cells provide output from the cortex (6) by way of axons coursing primarily in the subcellular zone." Kriegstein and Connors (1986). Open profiles: excitatory synaptic action; filled profiles: inhibitory synaptic action.
Table 1 | Summary of elements common to cortical circuits (Shepherd, 1988).

Pyramidal cells with apical and basal dendrites;

Excitatory inputs to distal dendritic spines of pyramidal cells;

Feedforward inhibition through inhibitory interneurons;

Feedback and lateral inhibition through pyramidal cell axon collaterals;

Feedback excitation through pyramidal cell axon collaterals;

Modulation of pyramidal cell activity through layered inputs to apical dendrite and soma.

in the main types of cerebral cortex." A detailed consideration of the anatomy and physiology of the cells and intrinsic circuits in the three regions of three-layer cortex, and in six-layer neocortex, supported the proposal. At this stage, those key specific circuits could be summarized in Table 1 .

It was emphasized that this common set of circuit elements was analogous to the common set of bones constituting the basic vertebrate skeleton. Just as the hand has been adapted from forelimb digits by evolutionary pressures, so have the circuit elements of the basic cortical microcircuit become adapted during neocortical evolution. It was suggested that these adaptations included addition of new neurons, new types of output neurons, new types of interneurons, and new types of intracortical connections and connection patterns. It was further suggested that novel physiological properties may have appeared, such as deployment of active properties in the dendrites, and the elaboration of second messengers and other biochemical mechanisms. In this way the basic circuit provides the substrate for evolving new functions during evolution. Specifically, 
... there is an underlying logic to the construction of cortical local circuits and microcircuits that provides a common modular framework that is adapted to generate the special properties of the neocortex.

Among the circuit elements that may be critical for cortical processing, the dendritic spines are of special interest. It was noted that the large number on distal dendrites moves the site of synaptic inputs away from having a direct effect on spike generation at the soma, and makes the effects of those inputs "contingent on specific combinations of inputs and cascades of non-linear interactions between the spine." (Shepherd, 1988).

This period in the 1980s also saw the introduction of neural networks based on parallel processing for the purpose of simulating brain function (Rumelhart and McClelland, 1986). These were based on representations of neurons as single summing nodes, in contrast with the complex dendritic branching patterns and spatiotemporal integration in real neurons. The networks are characterized by all-to-all connectivity, in contrast to the specific connectivity of most neurons. An aim of the review was to clarify the limitations of this network architecture by showing the elements of the local circuits - particularly including the properties of dendrites and dendritic spines, and the specificity of excitatory and inhibitory interactions - that should be built into neural network models in order to simulate more accurately human cognitive functions, a goal that unfortunately still is far from realized (see also Shepherd, 1990).

\section{A CANONICAL NEOCORTICAL CIRCUIT}

The emerging concept of a basic circuit for the neocortex was expressed in a distinct form in the "canonical cortical microcircuit" of Douglas et al. (1989). This was based on experimental studies in visual cortex of interactions between two populations of pyramidal neurons, superficial and deep, and a population of interneurons (Figure 6; stellate cells, being spiny, were grouped with the pyramidal cells). The pyramidal (and stellate) neurons are glutamatergic and excitatory, the interneurons GABAergic and inhibitory. Each pyramidal neuron population has intracortical connections onto three targets: itself (feedback excitation through its own axon collaterals); similarly on the other set of pyramidal neurons; and the population of inhibitory interneurons (giving rise to feed back inhibition onto its own population and onto the other population of pyramidal neurons). The inhibitory interneurons accordingly are excited by each population of pyramidal neurons and inhibit each population, as well as inhibiting themselves. Different weights of excitation and inhibition are indicated by the thickness of the arrows. The thalamic input is shown activating mainly the stellate cells of layer 4, which, being spiny and excitatory, are regarded as having properties similar to those of the spiny superficial pyramidal cells.

This scheme enabled Douglas et al. (2004) to summarize several important features of cortical connectivity and dynamics from their own and previous work. The preponderance of connections is between the excitatory pyramidal cells, including re-excitation. Because thalamic synapses account for only some $10 \%$ of the connections in the cortex, the excitatory and re-excitatory connections may be important in selectively amplifying the thalamic inputs. However, re-excitation is potentially dangerous in leading to hyperexcitability and seizures. Inhibition is therefore needed to oppose

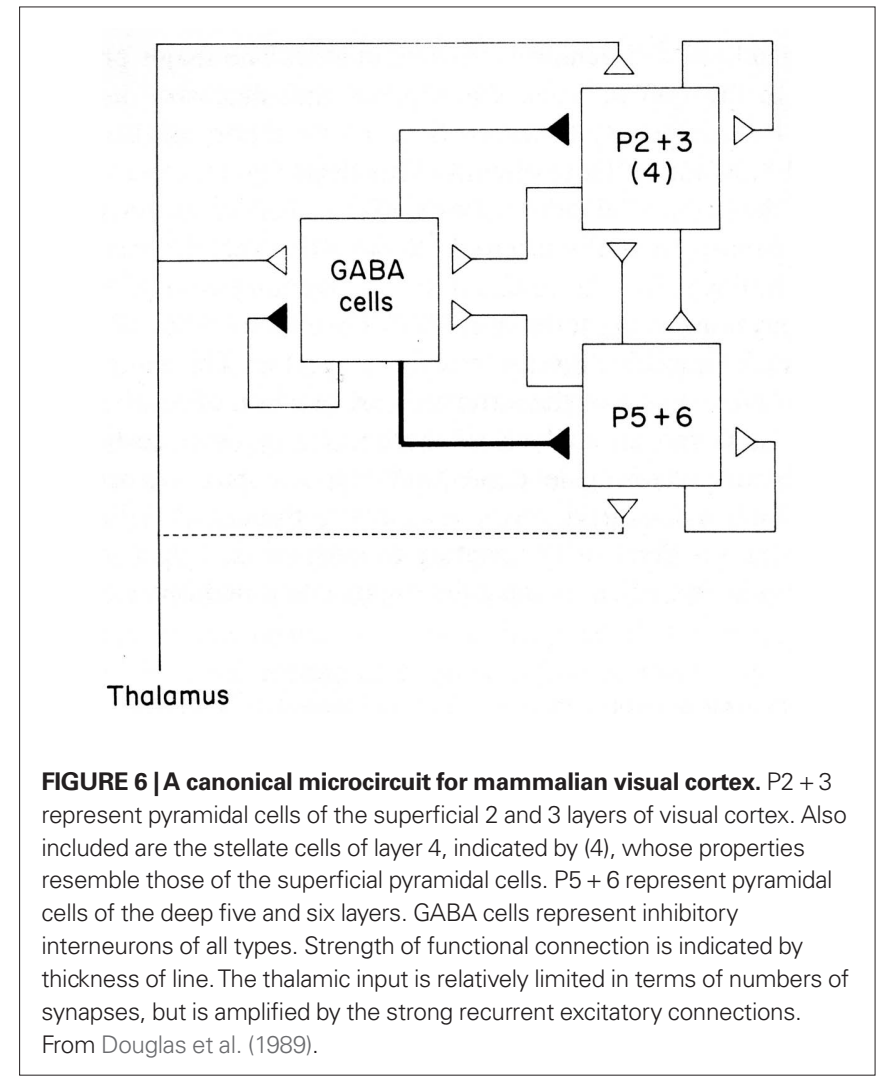

or modulate this potentially strong excitation. Cortical circuits can thus be seen to be poised on the knife edge of excitation restrained by inhibition, one of the risks of the computational power of the cortical microcircuit (see also below).

The canonical circuit of Figure 6 can be seen to depict in flowchart form the essential connectivity of the basic cortical circuit shown in Figure 3. It has been useful for testing for basic elements in neocortical microcircuits, as described further below.

\section{FROM THREE LAYERS TO SIX LAYERS}

In support of the hypothesis of Smith et al. (1980) and Kriegstein and Connors (1986), the intrinsic organization of three-layer cortical areas as a basis for the evolution of six-layer neocortex was made explicit in a hypothesis in 1994, which stated:

These facts suggest that the basic circuit for olfactory-hippocampalgeneral cortex may represent a framework that has been elaborated into the neocortex in the course of mammalian evolution.

The hypothesis is illustrated in the diagrams of Figure 7. The basic circuit common to three-layer cortices is shown in A. The common elements of primary afferents, intrinsic circuits for feedforward inhibition (FI) and lateral inhibition (LI), and RE, are indicated by the labels.

The possible evolutionary relation to six-layer neocortex is indicated by the arrow. The direct input from thalamus to pyramidal cells, characteristic of three-layer cortex, is indicated by the dashed lines. In addition, six-layer cortex has a new class of stellate cells, which also receive thalamocortical input, and relay it to 
A OLFACTORY-HIPPOCAMPAL-GENERAL CORTEX
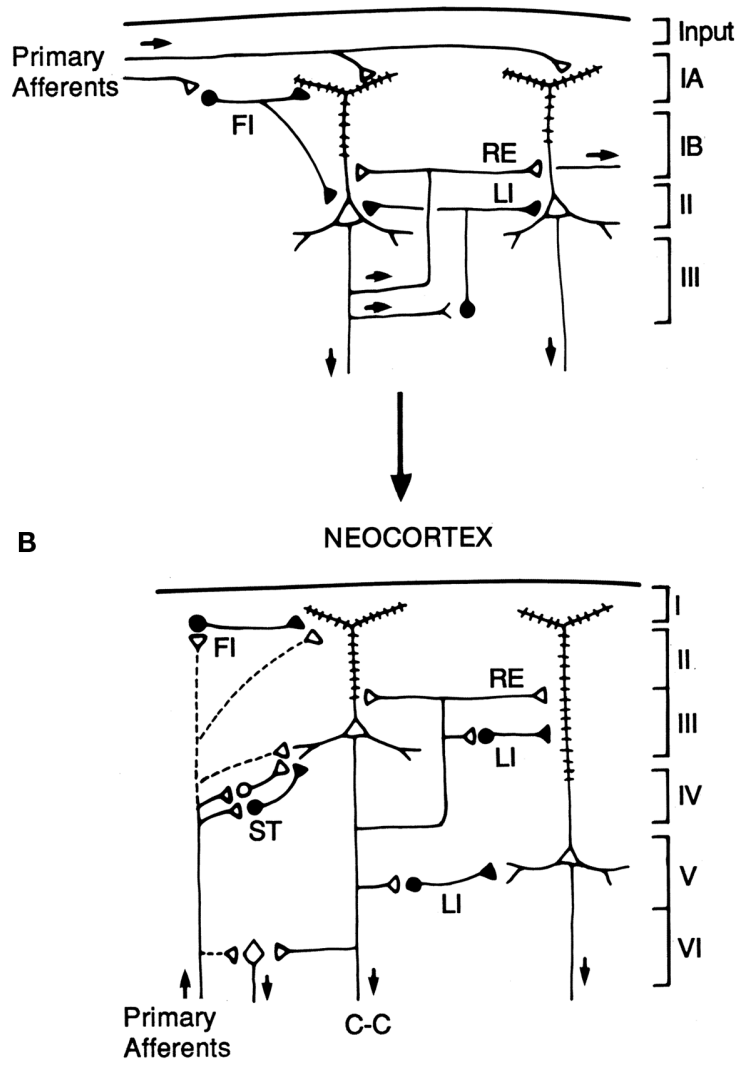

FIGURE 7 | Hypothesized relations between canonical microcircuits for three-layer simple cortex and six-layer neocortex. (A) Simplified representation of the three main types of three-layer microcircuits: olfactory (piriform) cortex, hippocampus; general (dorsal) reptilian cortex. Abbreviations: $\mathrm{Fl}$, feedforward inhibition; LI, lateral inhibition; RE, recurrent excitation. For the hippocampus, primary afferents represent the perforant pathway; RE represent the Schaffer collaterals, and LI represent local inhibitory feedback. Pyramidal cells and inhibitory interneurons as in Figure 3. Cortical layers shown on right. (B) Canonical microcircuit for neocortex. Abbreviations: same as A; C-C, cortico-cortical fibers; ST, stellate cell cortical layers shown on right. Arrows indicate direction of flow of activity. Open profiles: excitatory synaptic action; filled profiles: inhibitory synaptic action. From Shepherd (1994).

the pyramidal cells. In granular cortex such as the primary visual area, the stellate cells are concentrated in layer 4; in agranular cortex such as motor areas, the stellate cells are distributed in several layers. The stellate cells can be seen to constitute a kind of internal forward relay interposed between the afferents and the pyramidal cells, serving as a staging "preprocessing" site for transforming the thalamic input into its cortical form. This may be necessary because the thalamic input constitutes scarcely $10 \%$ of the synaptic connections in its layers of termination (Douglas and Martin, 2010); the vast majority come from intrinsic and cortico-cortical connections.

Apart from this difference in the input, the other main difference from three-layer cortex is the division into a superficial cortex (layers 1-3) and a deep cortex (layers 4-5), characterized by superficial and deep pyramidal cells, as indicated in the diagram. However, the diagram reiterates the original basic circuit of
Figure 1, in showing that the pyramidal cells have their intrinsic circuits for LI and RE (not all possible combinations are shown for simplicity).

With this approach it was possible to begin to identify properties that are special about the basic circuit of the neocortex. First, it is accessible to every major sensory input, either directly from olfactory cortex or indirectly through the thalamus. Similarly, it provides a wide variety of motor outputs, that reach all levels of the neuraxis, from the cortex itself through the basal ganglia and brainstem to the spinal cord. Second, it expands the single layer of pyramidal cells in dorsal cortex to the superficial (layers 2-3) and deep (layers 5,6) layers of neocortex. This greatly expands the combinatorial possibilities for intracortical processing. Third, in contrast to dorsal cortex where the afferents come in at the top, the afferents ascend from the depths and efferents descend through the same layers. This means that both input and output have potential access to all the cells in every layer. When the intrinsic circuits through the axon collaterals and interneurons are added, the result is that "the potential ways by which information can be integrated, stored, and recombined becomes enormous" (Shepherd, 1994). Fourth, whereas in most regions there are one or two types of output neuron, in the cortex each layer is the potential source of output, either locally between layers (cells in layer 1 and 4 ) or distantly (cells in layers 2,3 and 5,6). This means that each layer can function as a semi-independent input-output unit, defined by its own unique combination of inputs, intrinsic connections, interactions with other layers, and output targets.

The final advantage of six-layer "neocortex" is that it arose in a favorable position from dorsal "general" cortex. On the flanks of dorsal cortex were olfactory cortex on the ventral lateral side and hippocampus on the medial side, both hemmed in by their locations. By contrast, dorsal cortex had the opportunity to expand, but on one condition: that the brain case could expand to give it room. This occurred throughout mammalian evolution, enabling neocortex to enlarge individual areas such as the major sensory receiving cortices or motor areas, or adding new areas such as for speech, "in order to combine information from new combinations of inputs or control different combinations of output targets." (Shepherd, 1994). An expanded summary of these properties common to three-layer cortex and elaborated in six-layer cortex is provided in Table 2.

\section{TESTING THE HYPOTHESIS: RECENT STUDIES OF CORTICAL MICROCIRCUITS}

This microcircuit approach provides a framework within which to assess studies of cortical properties at the neuron and circuit level. We consider recent and current work from this perspective. This work has focused on the two main types of neuron: pyramidal neuron and interneuron, and the two main types of connections between them: recurrent excitatory and inhibitory pathways through the pyramidal cell axon collaterals. Within the pyramidal neurons, the information processing that occurs in their dendrites is of key importance. We consider each of these features in turn, beginning with the axon collateral pathways for RE and inhibition.

\section{OLFACTORY CORTEX AS A CONTENT-ADDRESSABLE MEMORY}

We are accustomed to thinking of the inputs to the hippocampus and to visual cortex in terms of spatial patterns, but what about olfactory cortex? Work in the olfactory bulb (Sharp et al., 1975; 
Table 2 | Current summary of the elements characterizing the microcircuit organization of three-layer and six-layer forebrain cortex.

1. Both three-layer and six-layer cortex are built on pyramidal cells with apical and basal dendritic trees.

2. Strong excitatory afferents are received in the spines of the branches of the apical and basal dendrites.

3. The spines and local branches create local sites with varying degrees of local information processing properties.

4. The spines, local branches, and main stems contain different combinations of $\mathrm{Na}, \mathrm{K}$, and $\mathrm{Ca}$ ionic channels, which create local sites of integration and boosting of input signals to reach the sites of action potential output in the cell body and axon hillock.

5. The pyramidal cells have well developed recurrent axon collaterals

6. The axon collaterals give rise to two main types of intrinsic circuit.

7. One type is direct feedback and lateral recurrent excitation.

8. This excitatory recurrent system has long lateral extensions, which enable widespread recombination of intrinsic excitation with the excitatory afferent input

9. The other type is feedback and lateral inhibition through inhibitory interneurons

10. Inhibitory interneurons are subdivided into multiple types which target different sites and levels of the soma-dendritic extent of the pyramidal cells.

11. Cortical information processing therefore involves a continual balance between excitatory and inhibitory circuits.

12. In three-layer cortex, these intrinsic circuits are organized around a single layer of pyramidal and pyramidal like neurons.

13. Five- and six-layer neocortex appears an expansion of the three-layer microcircuit into closely integrated superficial and deep layers.

14. Cortico-cortical afferents make synapses at different levels of the pyramidal cell soma-dendritic axis to excite, inhibit, or modulate the transfer of synaptic inputs and extent of backpropagating action potentials in the dendritic trees.

15. Brainstem systems provide differential modulation in different layers.

Stewart et al., 1979) using the 2-deoxyglucose activity mapping method showed that odor stimulation gives rise to spatial patterns of activity in the glomerular layer. Different odors produced different patterns, providing strong evidence that odor molecules are represented in the olfactory system by different spatial activity patterns, and that these are further processed by circuits in the olfactory bulb and olfactory cortex as the basis for odor perception and discrimination. This functional evidence for spatial patterns was strongly supported by the subsequent evidence for spatial organization of the projections of the olfactory receptor cells (Vassar et al., 1994; Ressler et al., 1994).

While the 2DG studies showed clear activity patterns in the olfactory bulb, they showed only diffuse uptake in the olfactory cortex (Sharp et al., 1977). This and other evidence indicated that the diffuse projections to the olfactory cortex, together with the internal system of long association fibers, provide for widespread processing of a given odor there. Based on these properties, Haberly (1985) suggested in a key paper that the olfactory cortex acts as a "content-addressable memory" system in which each site in the system contains information about the entire input. This fundamental insight has been the main organizing principle for understanding information processing in the olfactory cortex. Beginning with Wilson and Bower (1988) and Lynch and Baudry (1988) it has been incorporated into subsequent experimental studies, as well as computational models of olfactory cortex.

The olfactory patterns in the olfactory bulb have been termed "odor images" (see Xu et al., 2000). In the processing of these images, the olfactory bulb has been compared with visual area V1, and olfactory cortex with visual association cortex (Neville and Haberly, 2004). An analogy was drawn in this regard by Haberly (1985) with the visual association cortical area for processing information about faces. Thus, olfactory cortex, hippocampus, and dorsal cortex are all involved in processing information encoded as complex spatial patterns (see especially the review by Wilson and Stevenson, 2006).
Thanks to the pioneering studies of Lewis Haberly and more recently many others, much basic information is available on the mammalian olfactory pyramidal neurons and the olfactory cortical microcircuit. The afferent fibers in the LOT make excitatory glutamatergic synapses on the spines of distal apical dendrites of the pyramidal cells, acting on both AMPA and NMDA receptors. Synapses with similar properties are made by the axon collaterals that activate GABAergic inhibitory interneurons and also form the long re-excitatory association fibers. An addition to the classical microcircuit of Figure $\mathbf{1}$ is the feedforward inhibitory interneuron in the superficial layer of the cortex. This work has been summarized in Neville and Haberly (2004) and Wilson and Stevenson (2006). It has enabled detailed dissection of the excitatory and inhibitory circuits within the olfactory cortex, as indicated in Figure 8.

\section{COMPARISON OF OLFACTORY AND HIPPOCAMPAL MICROCIRCUITS}

We have seen that a general similarity was early recognized between the microcircuit organization of olfactory cortex and hippocampus (Figures 1 and 2). This idea has been supported by subsequent work. Figure 9 illustrates a close comparison by Neville and Haberly (2004) between the main excitatory circuits in the two systems. In the olfactory cortex, there is a sequence of input from the $\mathrm{OB}$ to the distal apical dendrites, an intrinsic long association feedforward recombining pathway from the anterior olfactory cortex, and the long recurrent association fibers directed mainly from the anterior cortex to the more posterior cortices. In the hippocampus, there is similarly a main afferent input to the distal apical dendrites, an intrinsic feedforward pathway through the dentate gyrus, and the recurrent association fibers directed from CA3 to CA1.

In this comparison, the main motif shared by these regions is the intrinsic sequential processing and recombination of input. It is known that both olfactory cortex and hippocampus are involved in processing spatial maps (olfactory cortex processes 


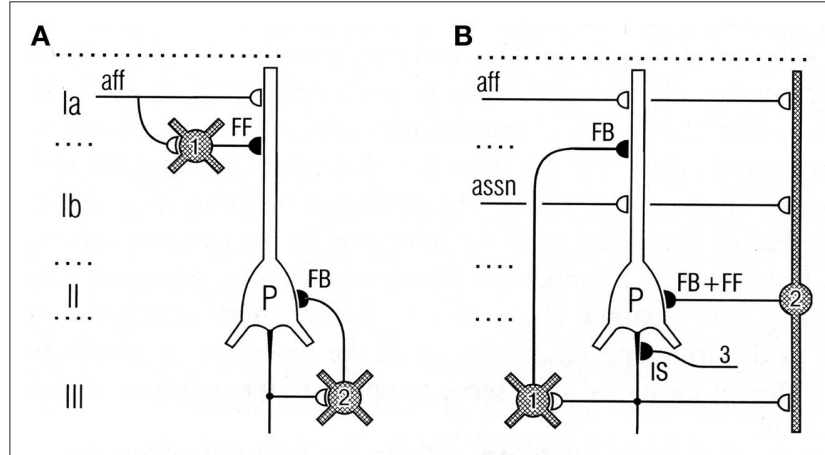

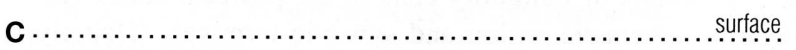

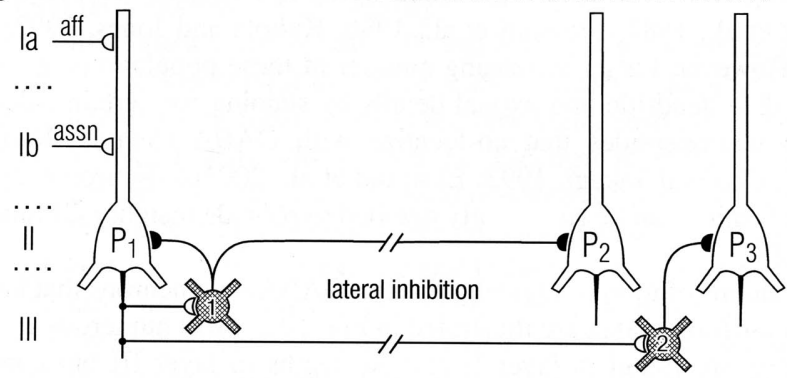

FIGURE 8 |Top: Circuits for excitatory input and different types of inhibition of pyramidal cells in the olfactory cortex. (A) Feedforward (FF) inhibitory (I) circuit from LOT afferents (aff) and feedback (FB) inhibitory circuit onto pyramidal cells (P). (B) Feedback and feedforward circuits from pyramidal cell axons, including inhibitory control of the initial segment (IS); assn, association fibers. (C) Pathways for lateral inhibition, through long axons of basket cell onto distant pyramidal cell, or long axon collateral of pyramidal cell onto distant basket cell. Open profiles: excitatory synaptic action; filled profiles: inhibitory synaptic action. From Neville and Haberly (2004).

high-dimensional odor maps, as noted above, and hippocampus processes spatial cognitive maps - O'Keefe and Nadel, 1978; Moser et al., 2010). Neville and Haberly (2004) conclude that "These intriguing similarities in neuronal circuitry suggest that the two systems operate on similar functional principles."

In addition to the sequential processing within these regions, one of the output targets of olfactory cortex is the hippocampus through entorhinal cortex. The hippocampus is thus involved in higher level olfactory processing. The inclusion of hippocampus in the olfactory pathway was a part of the traditional neuroanatomical concept of the "rhinencephalon," but was denied or ignored during the upsurge of interest in the hippocampus in the 1950s and 1960s. However, sequential processing from olfactory cortex to hippocampus is now increasingly recognized (Yokota et al., 1970; Lynch and Baudry, 1988), so it is time to put the hippocampus back in the olfactory pathway.

\section{RECENT STUDIES OF THE NEOCORTICAL CANONICAL MICROCIRCUIT}

Douglas et al. (2004) have suggested that their canonical cortical microcircuit model can apply, with fine-tuning of the connectivity and physiological properties, across the cortex, from visual to motor areas, justifying calling it a "canonical" circuit. They argue that

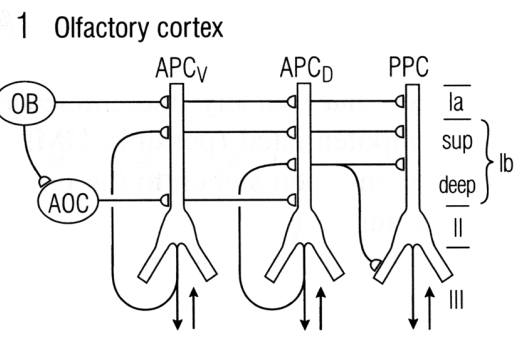

2 Hippocampal formation

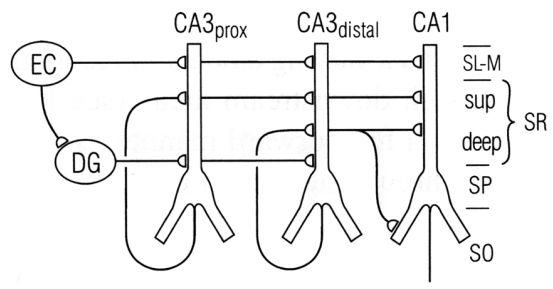

FIGURE 9 | Comparison between the microcircuit organization of olfactory cortex and hippocampus. "Note the parallels in both the horizontal dimension (connections between subdivisions) and the vertical dimension (laminar organization of fiber systems according to their areas of origin." Abbreviations: (1) OB, olfactory bulb; AOC, anterior olfactory cortex; APCV, ventral anterior piriform cortex; $\mathrm{APCD}$, dorsal anterior piriform cortex; PPC, posterior piriform cortex; sup, superficial. (2) EC, entorhinal cortex; DG, dentate gyrus; prox, proximal; dist, distal; SL-M, stratum lacunosummoleculare; SR, stratum radiatum; sup, superior; SP, stratum pyramidale; SO, stratum oriens. From Neville and Haberly (2004).

... simplicity encourages the convergence of theory and biology through common models, and such convergence is imperative if we are to understand how the synaptic organization of the neocortex produces the complexity of cortical function

supporting the theme of this review.

The canonical model stimulated further work quantitating the proposed connectivity. Binzegger et al. (2009) carried out an analysis of synaptic connectivity within the cortex based on the location of axonal terminals of HRP injected cells. The results showed that the cortex is dominated by the large population of superficial pyramidal cells; that these cells have many re-excitatory connections; and that they have a large input to deep pyramidal cells. The deep pyramidal cells are dominated by this input; in contrast, they have few re-excitatory collaterals onto themselves, and few excitatory connections back on to the superficial pyramidal cells. Computational network simulations showed how stability arises from the connectivity, membrane properties, and inhibitory connections. The thalamic input is amplified through the dynamic re-excitatory network as earlier predicted. A parallel study of reconstructions of dendritic and axonal arbors provided evidence of strong connectivity within a column from excitatory pyramidal cells to inhibitory interneurons, with weaker connectivity in the reverse direction (Stepanyants et al., 2008).

Another approach to analyzing cortical microcircuits has been through experiments with laser scanning photostimulation of caged glutamate release. These have revealed strong excitatory flow from upper to lower layer neurons in both sensory and motor 
cortex (e.g., Weiler et al., 2008), suggesting that motor output is controlled by a top-down "pre-amplifier-like network" of upperlayer neurons. Here we see again the advantages of six-layer cortex in multiplying the combinatorial possibilities of interlaminar connectivity.

In summary, the microcircuit approach continues to focus studies on essential subsystems for intrinsic excitation and reexcitation together with recurrent/lateral inhibition. As we have seen (Figure 7), the parallels include similarities - the retention of basic excitatory and inhibitory subsystems - and differences expansion to two main layers, and the addition of the stellate cell subsystem.

\section{RECENT STUDIES OF INFORMATION PROCESSING IN PYRAMIDAL CELL DENDRITES}

The pyramidal cell occupies a central place in the microcircuit organization of all the forebrain cortical regions. Attention therefore focuses on comparisons between the information capacities of the pyramidal cell dendrites. We consider several recent studies which address this issue.

\section{APICAL DENDRITES OF OLFACTORY CORTICAL PYRAMIDAL CELLS}

A recent study that has tested the olfactory cortex microcircuit has looked closely at the integrative properties of the apical dendrite of the pyramidal cell (Bathellier et al., 2009). These authors were intrigued by the finding (Poo and Isaacson, 2007) that olfactory bulb inputs vary widely in their potency in eliciting a pyramidal cell response. They wished to know whether this reflects numbers of input axons or strength of suprathreshold dendritic activity due to clustered inputs to a given dendrite. The methods used dual patch recordings in brain slices from pyramidal neurons activated by injected current or LOT fibers. Labeled cells had multiple apical branches 300-400 $\mu \mathrm{m}$ long. Dual patches on soma and distal dendrite showed that the dendrites were electrotonically relatively compact; for inputs in a distal dendrite, there was a maximum of 50\% current loss at the soma. The dendrites were only weakly active. They were able to support backpropagating action potentials, as in neocortical and hippocampal pyramidal neurons, but could generate only small local $\mathrm{Na}+$ spikes that had little effect at the soma. Also, unlike neocortex, they showed no dendritic $\mathrm{Ca} 2+$ or NMDA spikes, although $\mathrm{Ca} 2+$ entry occurred with backpropagating action potentials.

With regard to integrative activity in the apical dendrite, synaptic inputs following activation of axons in the LOT appeared to be uniformly distributed over distal dendrites. Bathellier et al. (2009) argue that this minimizes sublinear summation effects (no clustering). They conclude that many single fibers have contacts distributed widely over the dendritic tree, an arrangement that provides for efficient transmission of distributed co-active inputs. As a consequence, stimulus feature extraction must be based on linear summation at the soma of many inputs over many dendrites rather than clustered processing in targeted dendrites. They suggest that such clustering could be a neocortical pyramidal cell innovation.

Backpropagation of action potentials is shared with other cortical pyramidal cells, but is more variable in olfactory pyramidal cells as well as in turtle dorsal cortex (see below). This may be correlated with lack of reliability of plasticity of the input synapses (Poo and Isaacson, 2007). It is also correlated with the fact that in both olfactory and dorsal cortex the pyramidal cell dendrites are only weakly active. This points to active properties as possibly a specialization required for more complex processing in the hippocampus and neocortex.

\section{LOGIC OPERATIONS IN APICAL DENDRITES OF HIPPOCAMPAL PYRAMIDAL NEURONS}

Before the advent of dual patch recordings by Stuart et al. (1993), computational approaches provided the first insights into the information processing capabilities of active dendrites. Although the processing is universally regarded as integrative, what exactly is the nature of this integration, and what is the nature of the information that is processed?

This question was addressed with a computational study to test whether dendrites might be capable of generating logic operations. In a classic study, McCulloch and Pitts (1943) had shown that excitatory and inhibitory interconnections between nerve cells could generate basic logic operations of AND, OR, and AND-NOT; these three operations are sufficient for building a digital computer. This same paradigm transferred to equivalent interactions between dendritic spines within an apical dendritic tree of a pyramidal neuron such as in CA1 or CA3 of the hippocampus was tested by Shepherd and Brayton (1987). The results showed that in the presence of a thresholding mechanism in the spines, the basic logic operations emerged naturally from simple combinations of synaptic responses, all of them present in dendritic responses. AND operations are related to summation and coincidence detection; OR operations to simple responses of individual synapses; AND-NOT operations to inhibitory control, either at the site of an excited spine by an inhibitory input on an excited spine, or modulation of the output of the spine by a distant inhibitory input on the dendritic branch. The thresholding mechanisms can be the all-or-nothing response of a single spine to a single vesicle released at an active zone, or voltage gated $\mathrm{Na}+$ or $\mathrm{Ca} 2+$ channels in subjacent dendritic branch (Shepherd et al., 1989).

These operations appear inherent in a system of dendritic branches or dendritic spines containing one or more of these thresholding properties (see Figure 10). They confer upon the apical (and possibly basal) dendritic system the ability to carry out information processing at a distance from the cell body. In this way the global input-output functions of the cell become conditional on the summated effects of multiple semi-independent compartments carrying out sub-threshold information processing.

This model was tested by Poirazi et al. (2003), who provide a good summary of the possible significance of active dendritic properties in pyramidal neurons:

"There is general agreement that pyramidal cell dendrites contain a large number and variety of voltage-dependent channels distributed non-uniformly throughout the dendritic tree, which heavily influence the cell's integrative behavior. Recent evidence also suggests that elemental synaptic conductances may vary systematically as a function of dendritic location (Magee and Cook, 2000). However, there remain quite different views as to the functional role that these dendritic and synaptic channels may play. One view is that voltage-dependent dendritic currents and scaling of synaptic conductances exist to transform the complex and physically sprawling cell into a virtual "point neuron." According to this view, dendritic non-linearities may exist to (1) 


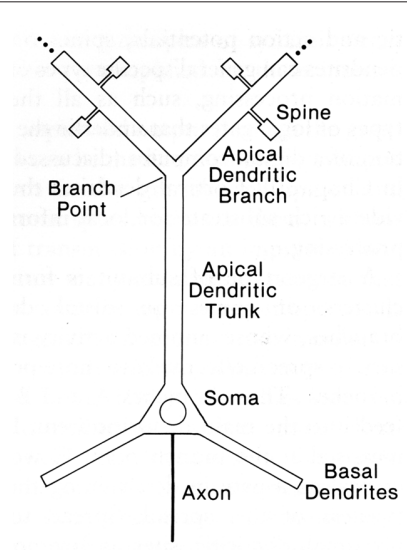

A Schematic representation of canonical pyramidal neuron

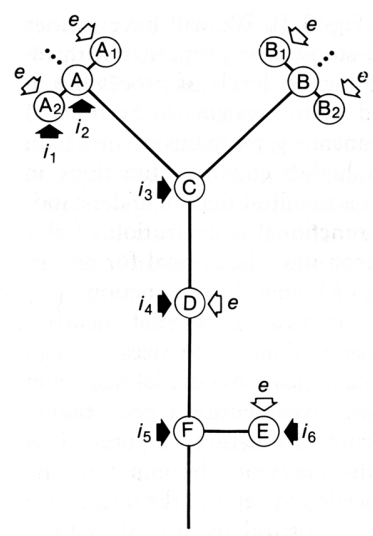

B Pyramidal neuron as a branching system of nodes for logic operations<smiles>CC1CC1C1CC1</smiles><smiles>CC1(C)C2CC3CC(CC3C3CC3)C1C2</smiles>

C Original McCulloch-Pitts representation of neurons as oversimplified nodes for logic operations
FIGURE 10 |Dendritic spines allow the pyramidal neuron to function as a complex multiunit processing system. (A): representation of a pyramidal neuron with multiple spine units. (B): representation of the pyramidal neuron with multiple sites for coincidence detection (A, B) in its spines and distal dendritic branches, with spread to summation points by passive or active mechanisms $(\mathrm{C})$, further spread boosted by active membrane and synaptic inputs) (D), similar mechanisms in the basal dendrites (E), and final summation at the ell body and axon hillock (F). Modulation occurs through excitation or inhibition at successive stages by layer-targeted inputs. Excitatory synapses indicated by open arrows; inhibitory synapses by filled arrows. (C): Examples of interconnections between point neurons that could implement OR (left), AND (middle), or more complex logic operations (right), as represented by McCulloch and Pitts (1943). From Shepherd (1994). make the cell more linear, by counteracting the classical synaptic non-linearity that arises from the summation of conductances (Bernander et al., 1994; Cash and Yuste, 1999), and in conjunction with synaptic scaling, they could (2) make the cell more functionally compact, by counteracting the distance-dependent attenuation of synaptic responses that arise from the cable properties of dendrites (Cauller and Connors, 1992; De Schutter and Bower, 1994; Magee and Cook, 2000). Both ideas emphasize the coupling of individual synapses to the cell body and the uniformity and linearity thereof.

A second view holds that the dendrites exist to create a number of independent functional compartments within which various kinds of non-linear computations can be carried out (Koch et al., 1983; Rall and Segev, 1987; Shepherd and Brayton, 1987; Mel, 1992a,b). Our results here support a particular version of this hypothesis in which the long, thin, unbranched, synapse-rich terminal dendrites may themselves act like classical neuron-like summing units, each with its own quasi-independent subunit nonlinearity. The cell body for its part, fed either directly by the basal dendrites or by the main trunk which acts as a high-efficiency conduit from the apical dendrites, sums together the dendritic subunit outflows to determine the cell's overall response. We have previously explored some of the functional implications of such a model (Mel et al., 1998; Mel, 1999; Archie and Mel, 2000; Poirazi and Mel, 2001)".

It may be seen that many of the themes in the exploration of dendritic properties of pyramidal neurons are brought together in this summary.

Poirazi et al. (2003) implemented the experimental findings in a neuron with simulations that provided evidence that these local active interactions endow the cortical pyramidal neuron with the ability to function as a "two-layer neural network" (Figure 11). This model has received repeated experimental support (Antic, 2003; Losonczy and Magee, 2006; Polsky et al., 2008).

We have seen that the apical dendrite of the olfactory pyramidal neuron has a relatively low density of $\mathrm{Na}+$ channels and is less able to generate local thresholding of responses to its distal synaptic inputs. It appears that this ability may have become more developed in the apical dendrites of hippocampal pyramidal neurons. We will see that this applies also to the apical dendrites of neocortical pyramidal neurons. Mammalian hippocampal pyramidal cell dendrites may thus have evolved toward some of the properties of neocortical pyramidal cells.

APICAL DENDRITES OF TURTLE DORSAL CORTICAL PYRAMIDAL NEURONS After Kriegstein and Connors (1986) there was unfortunately litthe interest in the synaptic organization of turtle dorsal cortex. However, one hopes this situation will change with the recent study by William Ross and his colleagues (Larkum et al., 2008) of the physiological properties of turtle pyramidal cells. They have built on the work and concepts of Kriegstein and Connors (1986), citing them that turtle dorsal cortex "presents a logical foundation for studying the more elaborate six-layered cortex," and that "There is a broad range of evidence establishing that the more elaborate six-layered neocortex was derived from the pallium (e.g., Mulligan and Ulinski, 1990; Reiner, 2000).” These statements indicate that the

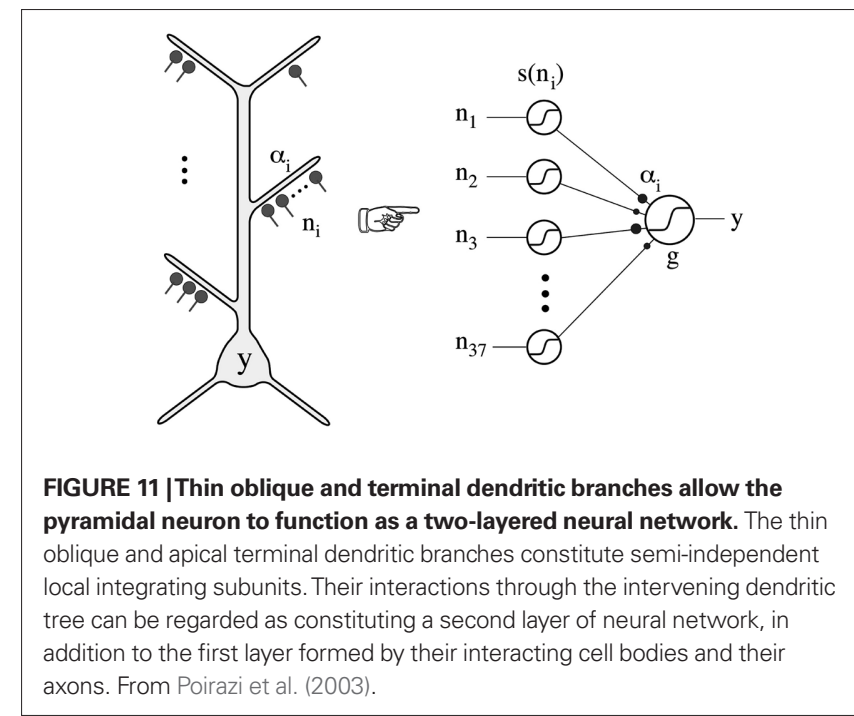


foundation laid by the work discussed above is gaining acceptance for application to cortical evolution, at least among those working at the level of synaptic organization and brain microcircuits.

In revisiting and updating the work of Kriegstein and Connors (1986), Larkum et al. (2008) were particularly interested in the dendritic properties of the pyramidal neurons. The combination of dual patch recordings and cell imaging techniques has transformed this key area of research, and the authors used both approaches in their study. Their basic findings can be summarized as follows.

First, the basic findings of Kriegstein and Connors (1986) were confirmed. Most turtle "pyramidal cells" are characterized by multiple apical dendrites and usually no basal dendrites. It may be noted that the pyramidal cells in mammalian olfactory cortex come in two varieties: one also has multiple apical dendrites and no basal dendrites, and is called a "semilunar cell"; the other has the more conventional apical and basal dendritic trees (see Neville and Haberly, 2004). Mammalian pyramidal cells, especially those in layer 2, can often have multiple apical dendrites (E. G. Jones, personal communication).

Despite this morphological difference, many basic electrophysiological properties of turtle pyramidal neurons were found to resemble those of mammalian neocortical pyramidal neurons. For example, intracellular current injection elicits repetitive spikes, which initiate preferentially near the soma; dendritic spike initiation occurs with stronger dendritic depolarization, and $\mathrm{Na}+-$ spike backpropagation is accompanied by Ca2+ influx. Among differences, the authors found that there was a lack of the broad $\mathrm{Ca} 2+$ spikes characteristic of the distal dendrites of hippocampal and neocortical pyramidal cells. This, together with the lack of an apical tuft, suggests that an apical tuft able to generate broad $\mathrm{Ca} 2+$ spikes may be "a more recent specialization of mammalian neocortical and hippocampal pyramidal neurons." The lack of dendritic $\mathrm{Ca} 2+$ spikes in the turtle is associated with the inability of a dendritic input to change the firing pattern in the soma from regular spiking to bursting. In neocortical pyramidal neurons this ability is believed to be necessary "to associate feedback inputs arriving in the tuft with feed forward inputs in the basal regions" (Larkum et al., 2008). Bursting may be a key property allowing a neuron to have a more potent effect on a target, which could be important for inducing plastic changes underlying learning and memory.

The results indicate that backpropagating action potentials and dendritic calcium influx are fundamental properties of cortical pyramidal cells. In mammalian pyramidal cells these properties have been especially implicated in mechanisms of synaptic plasticity. The fact that they are present in dorsal cortical pyramidal cells provides a fresh perspective, because it indicates that they were present in the basic three-layer cortical microcircuit. This indicates that mechanisms of plasticity that we ascribe to neocortical neurons and microcircuits in fact were already present in the three-layer precursors of those neurons and microcircuits. As the authors conclude:

...these findings encourage continued use of the turtle cortical slice preparation in seeking the characteristics that define the fundamental functional properties of cortical cells and circuits across a wide range of vertebrates.

\section{APICAL DENDRITES OF NEOCORTICAL PYRAMIDAL NEURONS}

Recent studies have revealed what appear to be some special properties of neocortical pyramidal cell dendrites. Of particular interest are the most distal dendritic branches of the apical dendrite that form a tuft within layer 1. Using multiple patches (see Figure 12, left), Larkum et al. (2009) showed that these branches can generate NMDA spikes, which in turn can generate $\mathrm{Ca} 2+$ spikes at the $\mathrm{Ca} 2+$ spike initiation zone where the branches converge onto the apical dendritic trunk, from which spikes can propagate to the soma (Figure 12, middle column). Previous studies have demonstrated NMDA spikes in the basal dendrites which can spread to initiate $\mathrm{Na}+$ spikes at the soma. This has suggested a unifying principle for the functional organization of the dendrites of the neocortical pyramidal neuron, in which the distal branches of the apical and basal dendrites generate NMDA spikes, which sum at their respective $\mathrm{Ca} 2+$ and $\mathrm{Na}+$ spike initiation sites, leading to the final summation at the axon hillock to generate the axonal action potential output (see Figure 12, right).

This new model represents a further refining of the concept of semi-independent compartments within the dendritic trees, to which the rules for summation of responses to generate basic logic operations still apply. It gives further support to the evidence that the single cell is a multi-compartment functional system, that cannot be represented by a single summing node as in neural network formulations. The neocortical microcircuit thus needs to be expanded to include the special properties of the apical and basal dendrites.

\section{CORTICAL INTERNEURONS AND CORTICAL COLUMNS}

Pyramidal cells appear to dominate the neuronal population of the cerebral cortex, with 70-80\% of the total, with interneurons comprising less $20-30 \%$ (as low as $10 \%$ in some estimates). However, the interneurons are attracting increasing interest because of their diversification into many subtypes. This is limited in olfactory cortex to the two main subtypes noted already: one deep type involved in feedback and LI onto the pyramidal cell somata, the other in superficial FI onto the pyramidal cell apical dendrites. In dorsal cortex the studies of Smith et al. (1980) showed a tremendous convergence of both input fibers and pyramidal cell axon collaterals onto one main type, suggesting that it played a key role in the inhibitory control of the pyramidal cells. Further studies are needed to test for subtypes within this population.

Diversification of subtypes reached its highest degree in hippocampus and neocortex. In the hippocampus, there are estimated to be at least 21 GABAergic interneuron subtypes, differentiated on the basis of multiple criteria: location of cell body, structure of dendritic trees, branching of axon, laminar and cellular synaptic targets, and molecular and physiological properties. As summarized by Somogyi (2010),

Interneurons provide multiple modulatory operations, such as changing threshold, synchronization, gain control, input scaling, and so on, and assist the network in the selection of pyramidal cells for cell assemblies.

In the neocortex, diversification is even more profligate. According to Markram (2010), there are 13 major anatomical types of interneuron. "Each anatomical type of neuron can express up to 8 of 15 major types of electrical behaviors, giving rise to as many as 200 morpho-electrical types of interneurons in a neocortical 


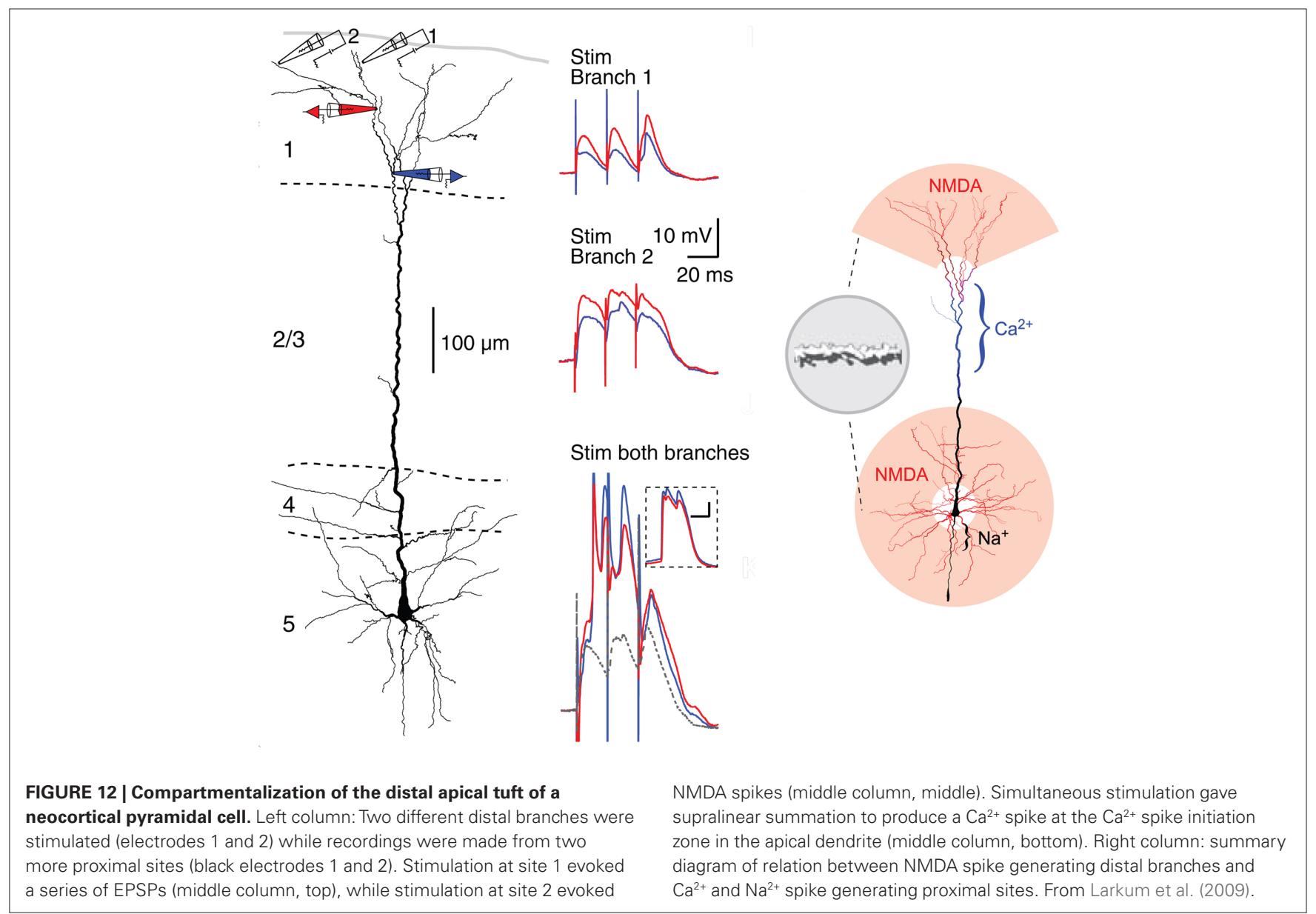

column...." There is evidence that the morpho-electrical type of identified pyramidal cell and interneuronal subtype is predictive of the type of interactions between the two, giving rise to a large number of combinatorial possibilities. These studies in rodents may not map adequately onto the variety of interneurons in primate and human neocortex (E. G. Jones, personal communication).

These local interactions in the neocortex are widely regarded to be organized within radial columns. This has been a tremendously fertile idea in thinking about microcircuit organization in the cortex over the past half century (Mountcastle, 1957; Hubel and Wiesel, 1962). Barrels in somatosensory cortex of certain animals are another example of modular organization in the neocortex. It is attractive to consider the cortical column as a neocortical invention. However, olfactory glomeruli, the nervous system's most distinctive anatomical and molecular module, may serve a similar function in the olfactory bulb in organizing the input to olfactory cortex (see Willhite et al., 2006), as may cell clusters in entorhinal cortex for its input to the hippocampus.

\section{ONE CORTICAL MICROCIRCUIT OR MANY? A BIOINFORMATICS APPROACH}

The diversity of neuron properties, interneurons, and intra and interlaminar connectivity being revealed by current studies appears to be a hallmark of neocortex. In the face of this diver- sity it may be asked whether the concept of a basic microcircuit for cerebral cortex is viable. As Nelson (2002) put it in a review of a meeting on mammalian cerebral cortex: is there "a single canonical microcircuit: a kind of basic wiring diagram which, although embellished, remains fundamentally unaltered from mouse to man and across all cortical regions"? Is there a single canonical microcircuit or are there many? Should we be lumpers or splitters?

The approach taken in this review in dealing with this question is built on how bioinformatics deals with gene and protein diversity. Taking G-protein coupled receptors (GPCRs) as an example, there is a motif of seven transmembrane domain receptors coupled to G-protein effectors, which constitutes a family. Within this family are subfamilies of receptors activated by different transmitter molecules, and subfamilies which activate different types of G-proteins. These different combinations sort themselves out into classes and subclasses (see the IUPHAR nomenclature website of the International Union of Basic and Clinical Pharmcology: http:// www.iuphar-db.org/index.jsp). This approach has been critical to the rise of molecular biology.

Applying this approach to cortical microcircuits, the basic elements we have identified, of pyramidal cells with apical and basal dendrites, giving rise to internal excitatory feedback and inhibitory feedback through interneurons, would describe the 
cerebral cortex family. The three- and six-layer cortical microcircuits would constitute subfamilies. Classes could be identified based on pyramidal cell properties and types of interneurons, as we have seen. Further diversification in relation to different cortical areas of different species might constitute subclasses. These suggestions indicate the need to have a conceptual framework such as the cortical microcircuit within which diversity can be prioritized. This framework in turn provides the basis for assessing the relative significance of each element of the diversity in the evolution of the cortex. It may be predicted that this hierarchical approach of bioinformatics can also be effective in promoting understanding of cortical microcircuit organization.

\section{CONCLUDING DISCUSSION}

The principles of organization at the microcircuit level underlying the evolution from three-layer to six-layer cortex may be summarized briefly in the following manner. The basic cortical microcircuit family consists of pyramidal cells interacting through recurrent excitatory and inhibitory intrinsic circuits, expanded from a single layer of pyramidal cell bodies in the subfamily represented by reptilian dorsal cortex, olfactory cortex, and hippocampus, to the multiple layers of pyramidal cell bodies of the mammalian neocortex subfamily. Within the neocortical subfamily, variations (classes and subclasses) at the molecular, cellular, and circuit level occur that are specific for each species.

A more complete inventory of the elements upon which the principles of cortical microcircuit organization are built is summarized in Table 2.

These properties taken together define the microcircuit organization of the cerebral cortex throughout most of vertebrate evolution. It may be proposed that this constitutes a unique set of properties found nowhere else in the vertebrate nervous system, uniquely adapted to the demands of providing the highest level of information processing in controlling and elaborating the behavior of any given vertebrate species. There are of course many variations on this theme in the basic cortical circuits suggested by a number of investigators (neocortex: DeFelipe and Jones, 2010; Markram, 2010; Georgopoulos and Stefanis, 2010; Svoboda et al., 2010; Wang, 2010; hippocampus: Buzsaki, 2006; Somogyi, 2010; entorhinal cortex: Moser et al., 2010; and olfactory cortex: Wilson and Barkai, 2010), but they all recognize at least the main features.

These shared properties are only the starting points for addressing the really interesting questions that will lead to identifying the unique subset of properties that characterizes neocortex. Although this goes beyond the focus of the present review, some promising directions may be indicated.

First (and foremost), what are the gene mechanisms that generate the expansion of the layers of microcircuits, to produce the quantal leap from three to six layers? Current studies of cortical development in rodents and in primates are providing critical insights into these processes (Cheung et al., 2007; Rakic, 2009; Montiel et al., this volume). A possible mechanism may be found in the fact that genesis of cortical layers occurs by the migration of new neurons along radial glia to their final layer in an inside-out sequence. New layers could have been added by mutations in the stop signals for the migrating neurons (P. Rakic, personal communication). A new initiative to map the entire human transcriptome, with focus on the cortex, is likely to give a new perspective on this question (Johnson et al., 2009).

How is the microcircuit concept related to the tremendous expansion of the neocortex that occurred during mammalian evolution, especially among certain species such as cetacea and primates, and especially humans? It is evidence that the neocortical microcircuit can be easily extended laterally to expand the cortex and differentiate into new regions. A leading hypothesis is that this cortical expansion occurred through elaboration from "protomaps" (Rakic, 2009). It may be hypothesized that each protomap contains a "protomicrocircuit" fine-tuned for its emerging cell properties and potential connectivity.

The physiological properties of the cortical cells require much more study. Building on the classical differentiation of cortical neurons into thick and thin spikes and regular and burst firing (McCormick et al., 1985), physiologists are identifying increasingly complex subtypes, especially of interneurons. The functions of the interneurons in synchronizing and desynchronizing cortical microcircuits through chemical and electrical synapses is a rapidly growing field in itself (Buzsaki, 2006; Mancilla et al., 2007). Cortical network activity is increasingly recognized as reflecting a balance between RE and inhibition (Haider et al., 2006). This balance is critical in all three types of mammalian cortex, as shown by the susceptibility of all of them to seizure activity from an excess of RE or reduction in recurrent inhibition.

Are there unique physiological properties of pyramidal cell dendrites in the pyramidal cells of humans compared with subhuman primates and other species that make their own critical contribution to human cognitive capabilities? Studies of human cortical cells are now possible from surgery for relief of epilepsy, which is providing valuable material for species-specific human properties at the biochemical and electrophysiological (Chen et al., 1996) level. And cells specific for humans open another angle on specific human properties (Allman et al., 2010).

How does this approach reconcile with other approaches to cortical evolution? A comprehensive review of cortical evolution (Striedter, 2005) has supported the basic focus here on reptilian dorsal cortex as the nearest approximation to the postulated precursor of mammalian neocortex. Reconciliation between current theories involving evolutionary routes through the dorsal ventricular ridge and the avian brain (Jarvis et al., 2005) is beyond the scope of this review. It can however be proposed that the concept of the microcircuit as an organizing principle, beginning with three-layer cortex, needs to be central to that discussion.

\section{ACKNOWLEDGMENTS}

This review is based on work generously supported by the National Institute for Deafness and other Communicative Disorders. I am grateful to Donald Wilson, Edward Jones, Zoltan Molnar, Ford Ebner, Pasko Rakic, and Gordon M. G. Shepherd for valuable comments on the manuscript. I dedicate this article to Lewis B. Haberly, student, colleague, friend, for his pioneering experiments and conceptual insights in constructing the microcircuit of the olfactory cortex and extending it to principles of cortical organization. 


\section{REFERENCES}

Allman, J. M., Tetreault, N. A., Hakeem, A. U., Manaye, K. F., Semendeferi, K., Erwin, J.M., Goubert, V., and Hof, P. R. (2010). The von Economo neurons in the frontoinsular and anterior cingulate cortex in great apes and humans. Brain Struct. Funct. 214, 495-517.

Andersen, P. (1960). Interhippocampal impulses. II. Apical dendritic activation of CAI neurons. Acta Physiol. Scand. 48, 178-208.

Andersen, P., Bliss, T. V. P., and Skrede, K. K. (1971). Lamellar organization of hippocampal excitatory pathways. Exp. Brain Res. 13, 222-238.

Antic, S. D. (2003). Action potentials in basal and oblique dendrites of rat neocortical pyramidal neurons. J. Physiol. 550, 35-50

Archie, K. A., and Mel, B. W. (2000). A model for intradendritic computation of binocular disparity. Nat. Neurosci. $3,54-63$

Bathellier, B., Margrie, T.W., and Larkum, M. E. (2009). Properties of piriform cortex pyramidal cell dendrites: implications for olfactory circuit design. J. Neurosci. 29, 12641-12652.

Bernander, O., Koch, C., and Douglas, R. J. (1994). Amplification and linearization of distal synaptic input to cortical pyramidal cells. J. Neurophysiol. 72, 2743-2753.

Biedenbach, M. A., and Stevens, C. F. (1969). Synaptic organization of cat olfactory cortex as revealed by intracellular recording. J. Neurophysiol. 32, 204-214.

Binzegger, T., Douglas, R. J., and Martin, K. A. (2009). Topology and dynamics of the canonical circuit of cat V1. Neural Netw. 22, 1071-1078.

Buzsaki, G. (2006). Rhythms of the Brain. New York: Oxford University Press.

Byrne, J.H., Castellucci, V. F., and Kandel, E. R. (1978). Contribution of individual mechanoreceptor sensory neurons to defensive gill-withdrawal reflex in Aplysia. J. Neurophysiol. 41, 418-431.

Cash, S., and Yuste, R. (1999). Linear summation of excitatory inputs by CA1 pyramidal neurons. Neuron 22, 383-394.

Cauller, L. J., and Connors, B. W. (1992). "Functions of very distal dendrites: Experimental and computational studies of layer I synapses on neocortical pyramidal cells," in Single Neuron Computation, eds. T. McKenna, J. Davis, and S. Zornetzer (Boston: Academic Press), 199-229.

Chen, W. R., Lee, S., Kato, K., Spencer, D. D., Shepherd, G. M., and Williamson, A. (1996). Long-term modifications of synaptic efficacy in the human inferior and middle temporal cortex. Proc. Natl. Acad. Sci. U.S.A. 93, 8011-8015
Cheung, A. F., Pollen, A. A., Tavare, A., DeProto, J., and Molnar, Z. (2007). Comparative aspects of cortical neurogenesis in vertebrates. J. Anat. 211 , 164-176.

Connors, B. W., and Kriegstein, A. R. (1986). Cellular physiology of the turtle visual cortex: distinctive properties of pyramidal and stellate neurons. $J$. Neurosci. 6, 164-177.

De Schutter, E., and Bower, J. M. (1994). Simulated responses of cerebellar Purkinje cells are independent of the dendritic location of granule cell synaptic inputs. Proc. Natl. Acad. Sci. U.S.A. 91, 4736-4740.

DeFelipe, J., and Jones, E. G. (2010) "Neocortical microcircuits," in Handbook of Brain Microcircuits, eds G. M. Shepherd and S. Grillner (New York: Oxford University Press), 5-14.

Douglas, R. J., Markram, H., and Martin, K. (2004). "Neocortex," in The Synaptic Organization of the Brain, ed. G.M. Shepherd (New York: Oxford University Press), 499-558.

Douglas, R. J., and Martin, K. A. C. (2010). "Canonical cortical circuits," in Handbook of Brain Microcircuits, eds G. M. Shepherd and S. Grillner (New York: Oxford University Press), 15-21.

Douglas, R. J., Martin, K. A. C., and Whitteridge, D. (1989). A canonical microcircuit for neocortex. Neural Comput. 1, 480-488.

Georgopoulos, A. P., and Stefanis, C. N. (2010). "The motor cortical circuit," in Handbook of Brain Microcircuits, eds G. M. Shepherd and S. Grillner (New York: Oxford University Press), 39-45.

Graybiel, A.M., and Grillner, S. (2006). Microcircuits: The Interface between Neurons and Global Brain Function. Cambridge, MA: MIT Press.

Grillner, S., Markram, H., De Schutter E., Silberberg, G., and LeBeau, F. E. (2005). Microcircuits in action-from CPGs to neocortex. Trends Neurosci. 28, 525-533.

Haberly, L. B. (1973a). Summed potentials evoked in opossum prepyriform cortex. J. Neurophysiol. 36, 775-788.

Haberly, L. B. (1973b). Unitary analysis of opossum prepyriform cortex. $J$. Neurophysiol. 36, 762-774.

Haberly, L. B. (1985). Neuronal circuity in olfactory cortex. Anatomy and functional implications. Chem. Senses $10,219-238$.

Haberly, L. B., and Shepherd, G. M. (1973) Current-density analysis of summed evoked potentials in opossum prepyriform cortex. J. Neurophysiol. 36 789-802.

Haider, G., Duque, A., Hasenstaub, A. R., and McCormick, D. A. (2006). Neocortical network activity in vivo is generated through a dynamic balance of excitation and inhibition. J. Neurosci. 26, 4535-4545.

Hildebrand, J. G., and Shepherd, G. M. (1997). Mechanisms of olfactory discrimination: converging evidence for common principles across phyla Annu. Rev. Neurosci. 20, 595-631.

Hubel, D. H., and Wiesel, T. N. (1962). Receptive fields, binocular interaction and functional architecture in the cat's visual cortex. J. Physiol. 160, 106-154

Jarvis, E. D., Güntürkün, O., Bruce, L. Csillag, A., Karten, H., Kuenzel, W. Medina, L., Paxinos, G., Perkel, D.J. Shimizu, T., Striedter, G., Wild J.M., Ball, G.F., Dugas-Ford, J., Durand, S.E. Hough, G.E, Husband, S., Kubikova, L., Lee, D.W., Mello, C.V., Powers, A., Siang, C., Smulders, T.V., Wada K., White, S.A., Yamamoto, K., Yu, J. Reiner, A., Butler, A.B., Avian Brain Nomenclature Consortium. (2005) Avian brains and a new understand ing of vertebrate brain evolution. Nat Rev. Neurosci. 6, 151-159.

Johnson, M. B., Kawasawa, Y. I., Mason, C. E., Kranik, Z., Coppola, G. Bogdanović, D., Geschwind, D. H. Mane, S. M., State, M.W., and Sestan, N. (2009). Functional and evolutionary insights into human brain development through global transcriptome analysis. Neuron 62, 494-509.

Kandel, E. R., Spencer, W. A., and Brinley, F. J. Jr. (1961). Electrophysiology of hippocampal neurons. I. Sequential invasion and synaptic organization. J. Neurophysiol. 24, 225-242.

Koch, C., Poggio, T., and Torre, V. (1983). Nonlinear interactions in a dendritic tree: localization, timing, and role in information processing. Proc. Natl. Acad. Sci. U.S.A. 80, 2799-2802.

Kriegstein, A. R., and Connors, B. W. (1986). Cellular physiology of the turtle visual cortex: synaptic properties and intrinsic circuitry. J. Neurosci. 6, 178-191.

Larkum, M. E., Nevian, T., Sandler, M., Polsky, A., and Schiller, J. (2009). Synaptic integration in tuft dendrites of layer 5 pyramidal neurons: a new unifying principle. Science 325 756-760.

Larkum, M. E., Watanabe, S., LasserRoss, N., Rhodes, P., and Ross, W. N. (2008). Dendritic properties of turtle pyramidal neurons. J. Neurophysiol. 99, 683-694.

Losonczy, A., and Magee, J. C. (2006) Integrative properties of radial oblique dendrites in hippocampal CA1 pyramidal cell neurons. Neuron 50, 291-307

Lynch, G., and Baudry, M. (1988). "Structure-function relationships in the organization of memory," in Pespectives in Memory Research, ed.
M. S. Gazzaniga (Cambridge, MA: MIT Press), 23-91.

Magee, J. C., and Cook, E. P. (2000). Somatic EPSP amplitude is independent of synapse location in hippocampal pyramidal neurons. Nat. Neurosci. 3, 895-903.

Mancilla, J. G., Lewis, T. J., Pinto, D. J., Rinzel, J., and Connors, B. W. (2007). Synchronization of electrically coupled pairs of inhibitory interneurons in neocortex. J. Neurosci. 27, 205802973.

Markram, H. (2010). "Microcircuitry of the neocortex," in Handbook of Brain Microcircuits, eds G. M. Shepherd and S. Grillner (New York: Oxford University Press), 22-30.

McCormick, D. A., Connors, B. W., Lighthall, J. S., and Prince, D. A (1985). Comparative electrophysiology of pyramidal and sparsely spiny stellate neurons of the neocortex. $I$. Neurophysiol. 54, 782-806.

McCulloch,W.W., and Pitts, W.H. (1943). A logical calculus of ideas immanent in nervous activity. Bull. Math. Biophys. 5, 115-133.

Mel, B.W. (1999). Computational neuroscience. Think positive to find parts. Nature 401, 759-760.

Mel, B.W. (1992a)."The clusteron: toward a simple abstraction for a complex neuron," in Advances in Neural Information Processing, Vol. 4, eds. J. Moody, S. Hanson, and R. Lippmann (San Mateo, CA: Morgan Kaufmann), 3542.

Mel, B.W. (1992b). NMDA-based pattern discrimination in a modeled cortical neuron. Neural. Comput. 4, 502-516.

Mel, B. W., Rudelman, D. L., and Archie, K.A. (1998). Translation invariant orientation tuning in visual complex cells could derive from intradendritic computations. J. Neurosci. 17, 4325-4334.

Moser, E. I., Witteer, P. M., and Moser, M.-B. (2010). "Entorhinal cortex,' in Handbook of Brain Microcircuits, eds G. M. Shepherd and S. Grillner (New York: Oxford University Press), 175-189.

Mountcastle,V. B.(1957). Modality and topographic properties of single neurons of cat's somatic sensory cortex. $J$. Neurophysiol. 20, 408-434.

Mulligan, K. A., and Ulinski, P. S. (1990). Organization of geniculocortical projections in turtles: isoazimuth lamellae in the visual cortex. J. Comp. Neurol. 296, 531-547.

Nelson, S. B. (2002). Cortical microcircuits: diverse or canonical? Neuron $36,19-27$.

Neville, K. R., and Haberly, L. B. (2004). "Olfactory cortex," in The Synaptic Organization of the Brain, ed. G. M. Shepherd (New York: Oxford University Press), 415-454. 
O'Keefe, J., and Nadel, L. (1978). The Hippocampus as a Cognitive Map. New York: Oxford University Press.

Phillips, C. G. (1959). Actions of antidromic pyramidal volleys ob single Betz cells in the cat. Quart. J. Exp. Physiol. 44, 1-25.

Poirazi, P., Brannon, T., and Mel, B. W. (2003). Pyramidal neuron as a two-layer neural network. Neuron 37, 989-999.

Poirazi, P., and Mel, B. W. (2001). Impact of active dendrites and structural plasticity on the memory capacity of neural tissue. Neuron 29, 779-796.

Polsky, A., Mel, B. W., and Schiller, J. (2008). Computational subunits in thin dendrites of pyramidal cells. Nat. Neurosci. 7, 621-627.

Poo, C., and Isaacson, J.S. (2007). An early critical period for long-term plasticity and structural modification of sensory synapses in olfactory cortex. J. Neurosci. 27, 7553-7558.

Rakic, P. (ed.). (1976). Local Circuit Neurons. Cambridge MA: MIT Press.

Rakic, P. (2009). Evolution of the neocortex: a perspective from developmental biology. Nat. Rev. Neurosci. 10, 724-735.

Rall, W., and Segev, I. (1987). “Functional possibilities for synapses on dendrites and on dendritic spines," in Synaptic Function, eds G. M. Edelman, W. Gall, and W. M. Cowan (New York: John Wiley and Sojs), 605-636.

Ramon y Cajal, S. (1911). Histologie du système nerveux de l'hommeet des vertébrés. Transl. L. Azoulay. Paris: Maloine. English translation by Swanson, N., and Swanson, L.W. (1995) Histology of the Nervous System. New York: Oxford University Press.

Reiner, A. J. (2000). A hypothesis as to the organization of cerebral cortex in the common amniote ancestor of modern reptiles and mammals. Novartis Found. Symp. 228, 83-102.

Ressler, K. J., Sullivan, S. L., and Buck, L. B. (1994). Information coding in the olfactory system: evidence for a stereotyped and highly organized epitope map in the olfactory bulb. Cell 79, 1245-1255.

Rumelhart, D. E., and McClelland, J. L. (eds). (1986). Parallel Distributed
Processsing. Explorations in the Microstructure of Cognition. Cambridge, MA: MIT Press.

Sharp, F. R., Kauer, J. S., and Shepherd, G. M. (1975). Local sites of activityrelated glucose metabolism in rat olfactory bulb during olfactory stimulation. Brain Res. 98, 596-600.

Sharp, F. R., Kauer, J. S., and Shepherd, G. M. (1977). Laminar analysis of 2-deoxyglucose uptake in olfactory bulb and olfactory cortex of rabbit and rat. J. Neurophysiol. 40, 800-813.

Shepherd, G. M. (1974). The Synaptic Organization of the Brain. New York: Oxford University Press.

Shepherd, G. M. (1978). Microcircuits in the nervous system. Sci. Am. 238, 93-103.

Shepherd, G. M. (1979). The Synaptic Organization of the Brain, 2nd Edn. New York: Oxford University Press.

Shepherd, G. M. (1988). "A basic circuit of cortical organization," in Perspectives in Memory Research, ed. M. S. Gazzaniga (Cambridge, MA: MIT Press), 93-134.

Shepherd, G. M. (1990). "The significance of real neuron architectures for neural network simulations," in Computational Neuroscience, ed. E. Schwartz (Cambridge, MA: MIT Press), 82-96.

Shepherd, G. M. (1994). Neurobiology, 3rd Edn. New York: Oxford University Press.

Shepherd, G. M., and Brayton, R. K. (1987). Logic operations are properties of computer-simulated interactions between excitable dendritic spines. Neuroscience 21, 151-165.

Shepherd, G. M., and Grillner, S. (eds). (2010). Handbook of Brain Microcircuits. New York: Oxford University Press.

Shepherd, G. M., Woolf, T. B., and Carnevale, N. T. (1989). Comparisons between active properties of distal dendritic branches and spines: implications for neuronal computations. J. Cogn. Neurosci. 1, 273-286.

Skrede, K. K., and Westgaard, R. H. (1971). The transverse hippocampal slice: a well-defined cortical structure maintained in vitro. Brain Res. 35, 589-593.

Smith, L. M., Ebner, F. F., and Colonnier, M. (1980). The thalamocortical projection in Pseudemys turtles: a quantitative electron microscopic study. J. Comp. Neurol. 190, 445-461.

Somogyi, P. (2010). "Hippocampus: intrinsic organization," in Handbook of Brain Microcircuits, eds. G. M. Shepherd and S. Grillner (New York: Oxford University Press), 148-164.

Stepanyants, A., Hirsch, J. A., Martinez, I. M., Kisvarday, A. F., Ferecsko, A. S., and Chklovskii, D. B. (2008). Local potential connectivity in cat primary visual cortex. Cereb. Cortex 18, 13-28.

Stewart, W. B., Kauer, J. S., and Shepherd, G. M. (1979). Functional organization of rat olfactory bulb analysed by the 2-deoxyglucose method. J. Comp. Neurol. 185, 715-734.

Striedter, G. (2005). Principles of Brain Evolution. Sunderland, MA: Sinauer.

Stuart, G. J., Dodt, H. U., and Sakmann, B. (1993). Patch-clamp recordings from the soma and dendrites of neurons in brain slices using infrared video microscopy. Pflugers Arch. 423, 511-518.

Svoboda, K., Hooks, B. M., and Shepherd, G. M. G. (2010). "Barrel cortex," in Handbook of Brain Microcircuits, eds G. M. Shepherd and S. Grillner (New York: Oxford University Press), 31-38. Swanson, L.W. (2000). What is the brain? Trends Neurosci. 23, 519-527.

Vassar, R., Chao, S. K., Sitcheran, R., Nunez, J. M., Vosshall, L. B., and Axel, R. (1994). Topographic organization of sensory projections to the olfactory bulb. Cell 79, 981-991.

Wang, X.-J. (2010). “Prefrontal cortex," in Handbook of Brain Microcircuits, eds G. M. Shepherd and S. Grillner (New York: Oxford University Press), 46-56

Weiler, N., Wood, L., Yu, J., Solla, S. A., and Shepherd, G. M. G. (2008). Topdown laminar organization of the excitatory network in motor cortex. Nat. Neurosci. 11, 360-366.

Willhite, D. C., Nguyen, K.T., Masurkar, A.V., Greer, C. A., Shepherd, G. M., and Chen, W. R.(2006). Viral tracing identified distributed columnar organization in the olfactory bulb. Proc. Natl. Acad. Sci. U.S.A. 103, 12592-12597.

Wilson, D. A., and Barkai, E. (2010). "Olfactory cortex," in Handbook of Brain Microcircuits, eds G. M. Shepherd and S. Grillner (New York: Oxford University Press), 263-276.

Wilson, M. A., and Bower, J. M. (1988). "A computer simulation of olfactory cortex with functional implications for storage and retrieval of olfactory information," in Neural Information Processing Systems, ed. D. Z. Andersen (New York: American Institute of Physics), 114-126.

Wilson, D. A., and Stevenson, R. J. (2006). Learning to Smell.Olfactory Perception from Neurobiology to Behavior. Baltimore, MD: Johns Hopkins.

Xu, F., Greer, C. A., and Shepherd, G. M. (2000). Odor maps in the olfactory bulb. J. Comp. Neurol. 422, 489-495.

Yokota, T., Reeves, A. G., and MacLean, P. D. (1970). Differential effects of septal and olfactory volleys on intracellular responses of hippocampal neurons in awake, sitting monkeys. J. Neurophysiol. 33, 96-107.

Conflict of Interest Statement: The authors declare that the research was conducted in the absence of any commercial or financial relationships that could be construed as a potential conflict of interest.

Received: 31 December 2010; paper pending published: 06 March 2011; accepted: 02 May 2011; published online: 23 May 2011.

Citation: Shepherd GM (2011) The microcircuit concept applied to cortical evolution: from three-layer to six-layer cortex. Front. Neuroanat. 5:30. doi: 10.3389/ fnana.2011.00030

Copyright () 2011 Shepherd. This is an open-access article subject to a nonexclusive license between the authors and Frontiers Media SA, which permits use, distribution and reproduction in other forums, provided the original authors and source are credited and other Frontiers conditions are complied with. 